\title{
Correction to: Angiomotin-p130 inhibits vasculogenic mimicry formation of small cell lung cancer independently of Smad2/3 signal pathway
}

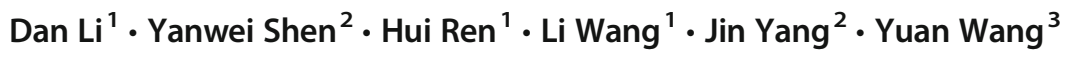 \\ Published online: 7 May 2021 \\ (C) Springer Science+Business Media, LLC, part of Springer Nature 2021
}

\section{Correction to: Journal of Bioenergetics and Biomembranes.} https://doi.org/10.1007/s10863-021-09891-7

The original version of this article unfortunately contained a mistake. The Acknowledgment should be:

This work was supported in part by Key Research and Development Project of Shaanxi Province (No. 2021SF-041) and Xi'an Science and Technology Project (No. 201805102YX10SF36(3)).

The original article has been updated.

Publisher's note Springer Nature remains neutral with regard to jurisdictional claims in published maps and institutional affiliations.

The online version of the original article can be found at https://doi.org/ 10.1007/s10863-021-09891-7

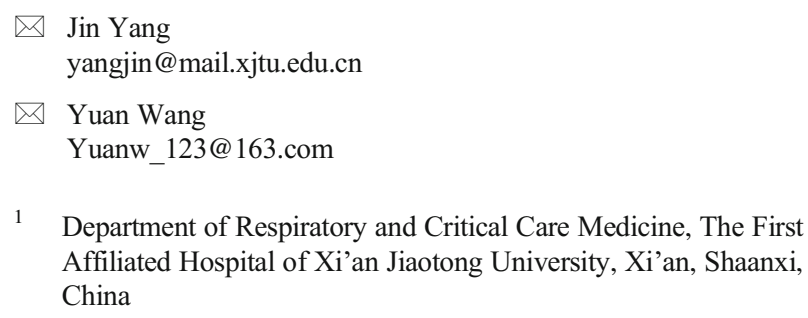

1 Department of Respiratory and Critical Care Medicine, The First Affiliated Hospital of Xi' an Jiaotong University, Xi'an, Shaanxi, China

2 Department of Medical Oncology, The First Affiliated Hospital of Xi'an Jiaotong University, Xi'an, Shaanxi, China

3 Department of Medical Imaging, The First Affiliated Hospital of Xi'an Jiaotong University, Xi'an, Shaanxi, People's Republic of China 